\title{
Contribution of High Plasma Triglycerides and Low High-Density Lipoprotein Cholesterol to Residual Risk of Coronary Heart Disease After Establishment of Low-Density Lipoprotein Cholesterol Control
}

\section{Citation}

Carey, Vincent J., Louise Bishop, Nancy Laranjo, Benjamin J. Harshfield, Carolyn Kwiat, and Frank M. Sacks. 2010. "Contribution of High Plasma Triglycerides and Low High-Density Lipoprotein Cholesterol to Residual Risk of Coronary Heart Disease After Establishment of Low-Density Lipoprotein Cholesterol Control." The American Journal of Cardiology 106 (6) (September): 757-763. doi:10.1016/j.amjcard.2010.05.002.

\section{Published Version}

doi:10.1016/j.amjcard.2010.05.002

\section{Permanent link}

http://nrs.harvard.edu/urn-3:HUL.InstRepos:30203403

\section{Terms of Use}

This article was downloaded from Harvard University's DASH repository, and is made available under the terms and conditions applicable to Other Posted Material, as set forth at http:// nrs.harvard.edu/urn-3:HUL.InstRepos:dash.current.terms-of-use\#LAA

\section{Share Your Story}

The Harvard community has made this article openly available.

Please share how this access benefits you. Submit a story.

\section{Accessibility}




\title{
Contribution of High Plasma Triglycerides and Low High-Density Lipoprotein Cholesterol to Residual Risk of Coronary Heart Disease After Establishment of Low-Density Lipoprotein Cholesterol Control
}

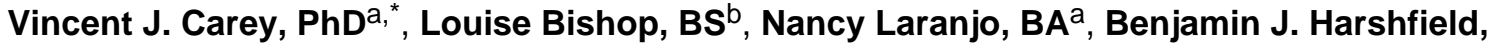 \\ BA $^{\mathrm{a}}$, Carolyn Kwiat, BA ${ }^{\mathrm{a}}$, and Frank M. Sacks, MD ${ }^{\mathrm{a}, \mathrm{b}}$ \\ Vincent J. Carey: stvjc@channing.harvard.edu \\ ${ }^{a}$ Channing Laboratory, Department of Medicine, Brigham and Women's Hospital, Harvard \\ Medical School, Boston, Massachusetts \\ ${ }^{b}$ Department of Nutrition, Harvard School of Public Health, Boston, Massachusetts
}

\begin{abstract}
To determine the relative contributions of triglycerides (TGs) and high-density lipoprotein (HDL) cholesterol in the residual risk of coronary heart disease (CHD) after the reduction of low-density lipoprotein (LDL) cholesterol to guideline-recommended levels, we conducted a hospital-based, case-control study with optimal matching in the strata of LDL cholesterol, gender, ethnicity, and age. The 170 cases and 175 controls were patients at Brigham and Women's Hospital (Boston, Massachusetts) from 2005 to 2008 who had an LDL cholesterol level $<130 \mathrm{mg} / \mathrm{dl}$. The cases had incident CHD, and the controls had diagnoses unrelated to CHD. The 170 cases and 175 controls had a mean LDL cholesterol level of 73 and $87 \mathrm{mg} / \mathrm{dl}$, respectively. The association between TG and HDL cholesterol levels and CHD risk was assessed using conditional and unconditional logistic regression analysis. The models investigated accommodated the possibility of an interaction between lipid factors. The odds of CHD increased by approximately $20 \%$ per $23-\mathrm{mg} / \mathrm{dl}$ increase in TGs and decreased by approximately $40 \%$ per 7.5-mg/dl decrease in HDL cholesterol. High TGs and low HDL cholesterol interacted synergistically to increase the odds ratio to 10 for the combined greatest TG ( $\geq 190 \mathrm{mg} / \mathrm{dl}$ ) and lowest HDL cholesterol quintiles ( $<30 \mathrm{mg} / \mathrm{dl})$. High TG levels were more strongly associated with CHD when the HDL cholesterol was low than average or high; and low HDL cholesterol levels were more strongly associated with CHD when the TGs were high. TGs and HDL cholesterol were associated with CHD in patients with a LDL cholesterol level of $\$ 70 \mathrm{mg} / \mathrm{dl}$, with a risk similar to, or greater than, those in the total group. In conclusion, high TG and low HDL cholesterol levels contribute strongly and synergistically to CHD when LDL cholesterol is well controlled. Thus, high TGs might have greater importance in patients with optimal rather than greater LDL cholesterol concentrations.
\end{abstract}

(C) 2010 Excerpta Medica, Inc. All rights reserved.

"Corresponding author: Tel: (617) 525-2265; fax: (617) 731-1541.

Publisher's Disclaimer: This is a PDF file of an unedited manuscript that has been accepted for publication. As a service to our customers we are providing this early version of the manuscript. The manuscript will undergo copyediting, typesetting, and review of the resulting proof before it is published in its final citable form. Please note that during the production process errors may be discovered which could affect the content, and all legal disclaimers that apply to the journal pertain. 
Several recent studies have focused on the role of triglyceride (TG) levels in cardiovascular disease risk. Sarwar et al ${ }^{1}$ performed a meta-analysis of 29 prospective studies and gave an estimate of 1.72 (95\% confidence interval 1.56 to 1.90) for the odds ratio (OR) comparing the risk of coronary heart disease (CHD) for those in the upper to lower tertiles of the TG distribution. A pooling of trials of statin treatment demonstrated that the TG level predicted CHD in the patients assigned to statin treatment as well as it did in the placebo group. ${ }^{2}$ Studies of secondary prevention ${ }^{3,4}$ of CHD found that TGs $<150 \mathrm{mg} / \mathrm{dl}$ was independently associated with a lower risk of CHD events in patients receiving high-intensity statin treatment, which produced especially low LDL cholesterol concentrations.

Similar reasoning can be applied to high-density lipoprotein (HDL) cholesterol as a risk factor in statin-treated patients. Low HDL cholesterol is associated with increased event rates in statin-treated patients, ${ }^{2}$ and the risk of low HDL cholesterol levels increases at lower LDL cholesterol levels. ${ }^{4,5}$ We hypothesized first that high TG and low HDL cholesterol levels are each associated with CHD events in those with LDL cholesterol at the goals recommended by the National Cholesterol Education Program Adult Treatment Panel III, and, second, that these 2 associations remain strong as the LDL cholesterol level decreases. To test these hypotheses, we interrogated an automated patient data registry at a major United States hospital to perform a matched case-control analysis of the relation between the TG levels and cardiovascular disease risk among subjects with LDL cholesterol levels <130 $\mathrm{mg} / \mathrm{dl}$.

\section{Methods}

The Brigham and Women's Hospital Research Patient Data Repository is a data warehouse for managing information on patients admitted to the hospital. ${ }^{6}$ Institutional review boardapproved data queries were performed to obtain information on all admissions from September 2005 to December 2008 involving acute coronary syndrome, ST-segment elevation myocardial infarction, or non-ST-segment elevation myocardial infarction, and unstable angina among patients aged 50 to 84 years at admission and who had an LDL cholesterol level of $<130 \mathrm{mg} / \mathrm{dl}$. Discharge summaries for all events were reviewed by the study staff to isolate information on demographics, CHD history, smoking, and treatment history. Lipid profiles obtained in the temporal vicinity of the CHD event were acquired from the hospital laboratory database. For the cases, lipid ascertainments occurred 6 days before admission to $\leq 2$ days after admission; for the controls, lipid measures were all obtained within 4 months (before or after) admission. The central $90 \%$ of the distribution of lipid ascertainment dates was bounded by 1 day before and 3 days after admission for cases and by 1 month before and 9 days after admission for controls.

The control series was constructed by examining admissions from September 2005 to December 2008 for subjects aged 50 to 84 years for diagnoses unrelated to coronary artery disease or myocardial infarction with a LDL cholesterol level of $<130 \mathrm{mg} / \mathrm{dl}$.

The records were subjected to uniform quality control procedures. A total of 345 participants (170 cases and 175 controls) were available for statistical analysis. Matched strata were formed for conditional logistic regression analysis ${ }^{7}$ using the optimal matching 
algorithm of Hansen and Klopfer. ${ }^{8}$ All subjects were characterized by their LDL cholesterol level, age, ethnicity (white vs nonwhite), and gender. Matched strata, each containing $\geq 1$ case and 1 control, were formed, subject to the constraints that all strata were homogenous with respect to gender and that the weighted sum (total Mahalanobis distance) of withinstratum discrepancies in LDL cholesterol level, age, and ethnicity (binary code) was minimized.

Conditional logistic regression analysis of the matched strata was performed using the maximum partial likelihood estimation in the survival package of $\mathrm{R}$, version 2.11.0 (available at: www.r-project.org). We formed integer scores for TG and HDL cholesterol that corresponded to quintiles of the overall distribution of each marker in the cohort. These scores were entered as linear terms in the conditional logistic regression analysis. In this formulation, which assumes that the log OR is linear across marker quintiles, the OR parameters are interpreted as the effect on risk of being in the "next quintile up" relative to a given quintile (below the top), in contrast to commonly reported comparisons of the extreme quintiles or tertiles.

\section{Results}

Table 1 lists the descriptive statistics on the subjects contributing data to the present study. The cohort was predominantly men (61\% overall, $75 \%$ among the cases, and $48 \%$ among the controls). The mean age for both cases and controls was 66 years (range 50 to 84). The LDL cholesterol and HDL cholesterol levels were lower on average for the cases (by 13 and $10 \mathrm{mg} / \mathrm{dl}$, respectively), and the TG levels were $12 \mathrm{mg} / \mathrm{dl}$ greater on average for the cases. Events defining case status were predominantly myocardial infarction (non-ST-segment elevation myocardial infarction or ST-segment elevation myocardial infarction; 45\%) followed by unstable angina (44\%), new-onset angina, and acute coronary syndrome. For 27 cases $(16 \%)$, previous myocardial infarction had been reported at admission. For 62 additional cases, some other manifestation of previous CHD, such as coronary artery bypass grafting, angioplasty, or angina, was noted at admission. A total of 249 subjects had indications of blood pressure measurements on admission. Overall, $33 \%$ had blood pressure measures indicating at least stage 1 hypertension ( $31 \%$ of cases and $35 \%$ of controls, $\mathrm{p}=$ 0.50 ). The use of lipid-lowering drugs at admission was noted for $61 \%$ of the cases and $33 \%$ of the controls ( $\mathrm{p}<0.001)$. Of the cases, those with a history of CHD had a mean LDL cholesterol of $68 \mathrm{mg} / \mathrm{dl}$. Those without such a history had a mean LDL cholesterol level of $76 \mathrm{mg} / \mathrm{dl}$.

For LDL cholesterol, $14 \%$ of cases, but $33 \%$ of controls, had levels $>100 \mathrm{mg} / \mathrm{dl}$. The contrast in TG distribution was less striking, with $26 \%$ of cases and $22 \%$ of controls with a value $>150 \mathrm{mg} / \mathrm{dl}$. For HDL cholesterol, the cases had much lower levels, with $74 \%$ reporting HDL cholesterol $<40 \mathrm{mg} / \mathrm{dl}$, compared to only $41 \%$ of controls with such low levels. These contrasts in low HDL cholesterol frequencies persisted across genders but at different levels. For men, $79 \%$ of cases but 53\% of controls had HDL cholesterol levels of $<40 \mathrm{mg} / \mathrm{dl}$. For women, the analogous percentages were $77 \%$ and $57 \%$ for HDL cholesterol of $50 \mathrm{mg} / \mathrm{dl}$. 
Application of the optimal matching algorithm of Hansen and Klopfer ${ }^{8}$ led to the formation of 112 strata of varying sizes that minimized the sum of the within-stratum discrepancies (Mahalanobis distance) in the matching factor values among the stratum members. Optimally, formed strata were predominantly 1:1 (case/control) matches (59 of 112) and included strata with other compositions ranging from 1:2 to 1:14 for 1-case strata, and 2:1 to 9:1 for multicase strata. The great majority (93\%) of strata contained $\leq 5$ subjects.

Matching was used to reduce the variability in factors we wished to control. We forced perfect matching on gender for all strata and used LDL cholesterol, age, and race as factors to be considered for matching. The within-stratum discrepancy for a matching factor is measured as the difference between the maximum and minimum values of the factor taken by those in the stratum. The strata generated by the optimal matching algorithm had a median discrepancy of $6 \mathrm{mg} / \mathrm{dl}$ in LDL cholesterol levels; the ninetieth percentile of LDL cholesterol discrepancy was $19 \mathrm{mg} / \mathrm{dl}$. The median discrepancy in age was 2 years, and the ninetieth percentile was 6 years. All strata were homogenous with respect to the white versus nonwhite ethnic classification.

Table 2 lists the estimated ORs and $\mathrm{p}$ values from the conditional logistic regression analysis of the optimally matched strata. Six models are presented to survey the roles of categorical and trend-based models in interpreting the data. Model 1 provides quintile-specific OR estimates for TG, with the lowest TG quintile as the reference. The OR was increased in TG quintiles 2 to 5 , representing the median range of 89 to $264 \mathrm{mg} / \mathrm{dl}$ compared to quintile 1 , with a median value of $61 \mathrm{mg} / \mathrm{dl}$. Some fluctuation from linearity was evident, with the greatest quintile OR 1 unit smaller than that of the fourth quintile. Model 2 simplified the representation of TG level to an integer score enumerating the quintiles. In this simple model, implicitly adjusted through matching for race, LDL cholesterol level, and age, 2 subjects who differed by occupying adjacent quintiles of the TG distribution would have a cardiovascular disease risk ratio of approximately $1.2(\mathrm{p}=0.03)$. The deviance test comparing models 1 and 2 had a value of 3.1 on $3 \mathrm{df}(\mathrm{p}=0.38)$; thus, the more parsimonious model 2, with OR function monotone in TG levels, was regarded as a satisfactory representation.

Models 3 and 4 present the analogous statistics describing the effects of differences in HDL cholesterol levels on CHD risk. In the univariate analysis of HDL cholesterol, estimated reductions in CHD risk of $60 \%$ to $85 \%$ were present for those with an HDL cholesterol level in the third to fifth quintiles. In the linear model 4 , occupancy of the next highest quintile of the HDL cholesterol distribution was associated with a $40 \%$ reduction in risk. The $3 \mathrm{df}$ deviance test comparing the fits of models 3 and 4 yielded $p=0.31$; thus, model 4 was an acceptable simplification. Model 5 of Table 2 uses TG and HDL cholesterol as simultaneous independent predictors of CHD risk. In model 5, we see estimates of HDL cholesterol effects consistent with those of the univariate model 4, and the TG effect seems substantially attenuated. Model 6 introduced a linear-by-linear interaction between TG and HDL

cholesterol. In model 6, which represents a borderline significant improvement of fit relative to model 5 ( $1 \mathrm{df}$ deviance, $\mathrm{p}=0.077$ ), the effect of transition to a higher TG quintile was an estimated 35\% increase in CHD risk (holding HDL cholesterol constant in the lowest 
quintile). Holding TG constant at its third quintile, the effect of transition to a higher quintile of HDL cholesterol would result in a $40 \%$ reduction in CHD risk.

Table 3 presents the point estimates to illustrate the relative risk patterns implied by the interaction model, in which the lowest quintile of TG and the highest quintile of HDL cholesterol is used as reference. The highly deleterious association of simultaneously greater TG and lower HDL cholesterol levels can be seen along the diagonals of Table 3. Figure 1 shows the intensification of CHD risk associated with greater TG levels within the lower categories of HDL cholesterol, with an even stronger association with CHD of lower HDL concentrations within the higher TG categories.

Table 4 presents similar statistics obtained on the subcohort of 128 subjects ( 82 cases and 46 controls) with LDL cholesterol levels $<70 \mathrm{mg} / \mathrm{dl}$. This subsample was optimally rematched to 41 strata ranging in size from 2 to 6 , using the same criteria and constraints used for the full cohort. In models 7 and 8, the TG associations with CHD were statistically significant, the odds of CHD increasing by a factor of $2.3(p=0.002)$ when a subject whose TG value was within a given tertile was compared with a subject with a TG value within the tertile just below (median for tertiles of 68,121 , and $219 \mathrm{mg} / \mathrm{dl}$ ). In contrast, the OR for an adjacent higher TG tertile was estimated at only 1.2 in the subsample with a LDL cholesterol level $>70 \mathrm{mg} / \mathrm{dl}$. For HDL cholesterol in the subsample with LDL cholesterol of $\leq 70 \mathrm{mg} / \mathrm{dl}$, the OR for CHD was estimated at $0.6(\mathrm{p}=0.07)$ for increasing HDL tertile scores (median for tertiles of 25,34 , and $46 \mathrm{mg} / \mathrm{dl}$ ). When both TG and HDL cholesterol were used to model CHD in those with LDL cholesterol levels $<70$, only TGs exhibited statistically significant effects on CHD risk (Table 4, models 9 and 10).

A number of analyses were conducted to explore the sensitivity of inferences to model structures used in Table 2. First, quadratic alternatives to the linear forms of models 2, 4, and 5 of Table 2 were assessed. None of these alternatives led to a significantly enhanced fit (minimum $\mathrm{p}>0.12$ ). Second, ordinary logistic regression analysis was used in an unmatched analysis of the full cohort. A simple linear adjustment for log-transformed LDL cholesterol was used, in addition to adjustments for gender, race, and age. Main effects-only models fit for TG and HDL separately were consistent with the matched analysis models 2 and 4 from Table 2 , and the TG $\times$ HDL interaction term was borderline significant $(\mathrm{p}=0.08)$. These findings indicate that the matching and modeling procedures of Tables 2 to 4 were reasonable. To address concerns regarding the variable timing of the lipid measurements relative to the date of admission for CHD or control event, we restricted the data to 274 subjects (163 cases and 111 controls) whose TG measurements were taken within 4 days of admission, an interval noted by Pitt et $\mathrm{al}^{9}$ within which lipid measures are relatively stable after acute coronary syndrome. The matching algorithm was reapplied to this subcohort for assessment of the robustness of the estimated lipid effects to the variable timing in the ascertainment of the lipid levels in the ascertainment of the lipid levels, and no qualitative impacts were observed. To explore the possible effects of hypertension or statin use on reported associations, we rematched and reanalyzed the data using 249 subjects for whom the hypertensive status could be determined. The OR associated with hypertension was approximately 0.9 ( $\mathrm{p}>0.8$ ) for both TG and HDL (Table 2, models 2 and 4), and the inclusion of hypertension did not alter the subcohort-based estimates of TG and HDL 
effects. A similar insensitivity of the main findings was observed when including an indicator of the use of lipid-lowering medications at admission.

\section{Discussion}

The present hospital-based matched case-control study of CHD risk in relation to simultaneous variations in TG and HDL cholesterol levels has provided new evidence of the residual risk of disease associated with high TG and low HDL cholesterol levels in the presence of LDL cholesterol control. The strengths of the presented analyses include the use of population data obtained during the previous 3 years; the use of optimal matching to create strata that were homogenous with respect to gender and race and reasonably homogenous with respect to age and LDL cholesterol levels; and the use of straightforward statistical analyses to identify trends and interactions among key biomarkers of cardiovascular disease risk. The limitations of the present study included the nature of the population analyzed, which was derived from the catchment area of a specific tertiary care center; the retrospective nature of the study, in which lipid measures could not be obtained at specified calendar intervals before the index event; the lack of availability of uniform information on potential confounders of lipid-CHD risk associations, given the basis of the study using an electronic records database; and the possibility that the hospital-based control series included those with some morbidity related to CHD.

LDL cholesterol is appropriately the principal lipid target for treatment, ${ }^{10}$ and CHD event rates can be reduced by this treatment in proportion to the extent of the reduction in LDL cholesterol. ${ }^{2}$ However, CHD has continued to progress to serious events in patients whose LDL cholesterol has been lower than the treatment goals, a phenomenon called "residual risk." The principal finding of the present study was that low HDL cholesterol and high TG levels each contribute to the residual risk by their association with hospitalizations for CHD in patients whose LDL cholesterol was remarkably low, most well below the treatment target of $100 \mathrm{mg} / \mathrm{dl}$ for those with CHD or otherwise at high risk, and nearly $1 / 2$ below the optional high-intensity treatment target of $70 \mathrm{mg} / \mathrm{dl}$ for those at very high risk. ${ }^{10}$ About $1 / 2$ of these patients had been taking statins at the time of the CHD event.

Mechanistically, HDL is essential to maintain cholesterol homeostasis between the arterial vasculature and liver and other organs. ${ }^{11}$ When this system of HDL-mediated reverse cholesterol transport is defective, such as in patients who cannot transfer cholesterol from the macrophages in the arterial intima to HDL, early, severe atherosclerosis and CHD results. ${ }^{12,13}$ The findings of the present study support such a central role for HDL cholesterol because low HDL cholesterol levels had a strong adverse association with CHD even when the LDL cholesterol was at optimal low levels.

TG are transported in plasma within lipoproteins, mainly very-low-density lipoprotein (VLDL). The concentration of VLDL is a strong predictor of events, more so than TGs. ${ }^{14}$ VLDL is a diverse group of particles, some having a stronger association with CHD than others. Some VLDLs contains an apolipoprotein, apolipoprotein C-III, which impairs the metabolism of VLDL ${ }^{15}$ and directly activates the atherogenic and inflammatory processes in the vascular endothelial cells and monocytes. ${ }^{16}$ Thus, apolipoprotein C-III containing VLDL 
and its metabolite apolipoprotein C-III- containing LDL are considered especially athergenic lipoprotein types, and their plasma concentration predicts CHD. ${ }^{17,18}$ These lipoproteins do not correlate with LDL cholesterol. When LDL cholesterol is low, the proportion of VLDLs and LDLs that is contains apolipoprotein C-III is high. Thus, we speculated that the high residual risk associated with TGs in the setting of optimal LDL cholesterol levels might be related to a greater concentration of atherogenic apolipoprotein C-III-containing lipoproteins. We have concluded that CHD occurring in patients with LDL cholesterol levels well below treatment goals (i.e., "residual risk") is associated strongly with low HDL cholesterol or high TG levels, and the combination is at least additive to the OR and, possibly, synergistic. These findings contribute to the rationale for considering low HDL and high TG levels, especially when they occur together, in quantifying the risk level to select the type and intensity of treatment.

\section{Acknowledgments}

We thank the 2 anonymous referees for their helpful comments. Dr Carey had full access to all the data in the present study and takes responsibility for the integrity of the data and accuracy of the data analysis.

Supported by the Residual Risk Reduction Initiative $\left(\mathrm{R}^{3} \mathrm{I}\right)$ Foundation (available at www.r3i.org). This Foundation has been a recipient of financial sponsorship solely from Solvay Pharmaceuticals (Abbott, Abbott Park, Illinois), although additional sponsors are actively sought. We have developed the methods and content for this research project and report with complete academic independence from the corporate sponsor of the Foundation.

\section{References}

1. Sarwar N, Danesh J, Eiriksdottir G, Sigurdsson G, Wareham N, Bingham S, Boekholdt SM, Khaw KT, Gudnason V. Triglycerides and the risk of coronary heart disease: 10,158 incident cases among 262,525 participants in 29 Western prospective studies. Circulation. 2007; 115:450-458. [PubMed: 17190864]

2. Baigent C, Keech A, Kearney PM, Blackwell L, Buck G, Pollicino C, Kirby A, Sourjina T, Peto R, Collins R, Simes R. Efficacy and safety of cholesterol-lowering treatment: prospective metaanalysis of data from 90,056 participants in 14 randomised trials of statins. Lancet. 2005; 366:12671278. [PubMed: 16214597]

3. Miller M, Cannon CP, Murphy SA, Qin J, Ray KK, Braunwald E. Impact of triglyceride levels beyond low-density lipoprotein cholesterol after acute coronary syndrome in the PROVE IT-TIMI 22 trial. J Am Coll Cardiol. 2008; 51:724-730. [PubMed: 18279736]

4. Sacks FM, Tonkin AM, Craven T, Pfeffer MA, Shepherd J, Keech A, Furberg CD, Braunwald E. Coronary heart disease in patients with low LDL-cholesterol: benefit of pravastatin in diabetics and enhanced role for HDL-cholesterol and triglycerides as risk factors. Circulation. 2002; 105:14241428. [PubMed: 11914249]

5. Barter P, Gotto AM, LaRosa JC, Maroni J, Szarek M, Grundy SM, Kastelein JJ, Bittner V, Fruchart JC. HDL cholesterol, very low levels of LDL cholesterol, and cardiovascular events. N Engl J Med. 2007; 357:1301-1310. [PubMed: 17898099]

6. Zeng QT, Goryachev S, Weiss S, Sordo M, Murphy SN, Lazarus R. Extracting principal diagnosis, co-morbidity and smoking status for asthma research: evaluation of a natural language processing system. BMC Med Inform Decis Mak. 2006; 6:30. [PubMed: 16872495]

7. Breslow N. Covariance adjustment of relative-risk estimates in matched studies. Biometrics. 1982; 38:661-672. [PubMed: 7171694]

8. Hansen B, Klopfer S. Optimal full matching and related designs via network flows. J Comput Graph Stat. 2006; 15:609-627.

9. Pitt B, Loscalzo J, Ycas J, Raichlen JS. Lipid levels after acute coronary syndromes. J Am Coll Cardiol. 2008; 51:1440-1445. [PubMed: 18402897] 
10. Grundy SM, Cleeman JI, Merz CN, Brewer HB Jr, Clark LT, Hunninghake DB, Pasternak RC, Smith SC Jr, Stone NJ. Implications of recent clinical trials for the National Cholesterol Education Program Adult Treatment Panel III guidelines. Circulation. 2004; 110:227-239. [PubMed: 15249516]

11. Rader DJ. Molecular regulation of HDL metabolism and function: implications for novel therapies. J Clin Invest. 2006; 116:3090-3100. [PubMed: 17143322]

12. Assmann, G.; Schmitz, G.; Brewer, HB, Jr. Familial high density lipoprotein deficiency: Tangier disease. In: Scriver, CR.; Beaudet, AL.; Sly, WS.; Valle, D., editors. The Metabolic and Molecular Bases of Inherited Disease. New York: McGraw-Hill; 1995. p. 1181-1194.

13. Brunham LR, Singaraja RR, Hayden MR. Variations on a gene: rare and common variants in ABCA1 and their impact on HDL cholesterol levels and atherosclerosis. Annu Rev Nutr. 2006; 26:105-129. [PubMed: 16704350]

14. Sacks FM, Alaupovic P, Moye LA, Cole TG, Sussex B, Stampfer MJ, Pfeffer MA, Braunwald E. VLDL, apolipoproteins B, CIII, and E, and risk of recurrent coronary events in the Cholesterol and Recurrent Events (CARE) trial. Circulation. 2000; 102:1886-1892. [PubMed: 11034934]

15. Zheng C, Khoo C, Ikewaki K, Sacks FM. Rapid turnover of apolipoprotein C-III-containing triglyceride-rich lipoproteins contributing to the formation of LDL subfractions. J Lipid Res. 2007; 48:1190-1203. [PubMed: 17314277]

16. Kawakami A, Aikawa M, Alcaide P, Luscinskas FW, Libby P, Sacks FM. Apolipoprotein CIII induces expression of vascular cell adhesion molecule-1 in vascular endothelial cells and increases adhesion of monocytic cells. Circulation. 2006; 114:681-687. [PubMed: 16894036]

17. Lee SJ, Campos H, Moye LA, Sacks FM. LDL containing apolipoprotein CIII is an independent risk factor for coronary events in diabetic patients. Arterioscler Thromb Vasc Biol. 2003; 23:853868. [PubMed: 12637336]

18. Sacks FM, Tonkin AM, Shepherd J, Braunwald E, Cobbe S, Hawkins CM, Keech A, Packard C, Simes J, Byington R, Furberg CD. Effect of pravastatin on coronary disease events in subgroups defined by coronary risk factors: the Prospective Pravastatin Pooling Project. Circulation. 2000; 102:1893-1900. [PubMed: 11034935] 


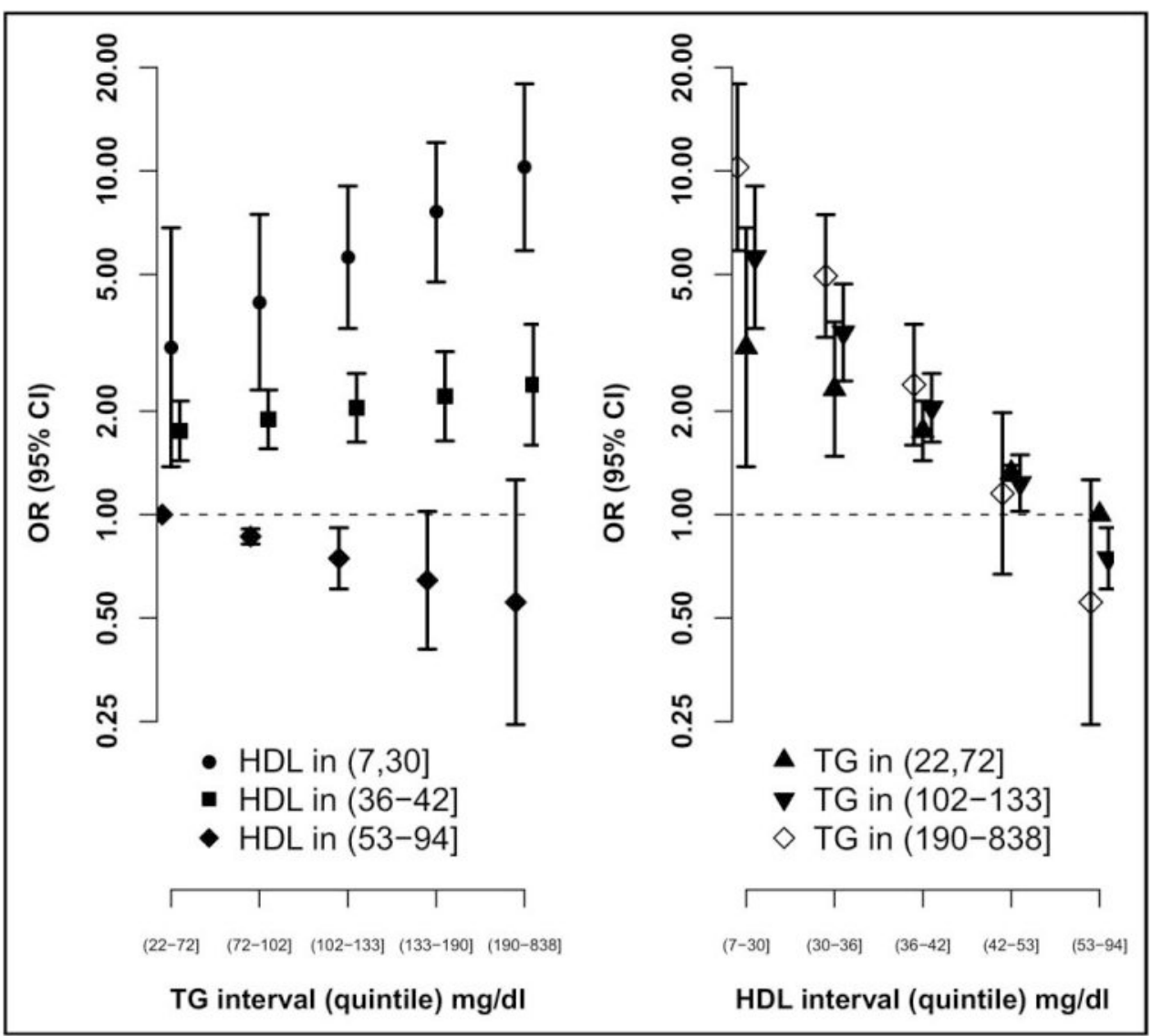

Figure 1.

(Left) ORs for CHD according to TG and HDL levels. Filled circles, estimates of OR for those in TG categories specified on $\mathrm{x}$-axis and lowest quintile of HDL (HDL range 7 to 30 $\mathrm{mg} / \mathrm{dl}$ ); filled boxes, analogous OR estimates for those in third quintile of HDL (HDL range 36 to $42 \mathrm{mg} / \mathrm{dl}$ ); filled diamonds, OR estimates for those in highest quintile of HDL (HDL range 53 to $94 \mathrm{mg} / \mathrm{dl}$ ). (Right) Open diamonds, OR estimates for those in highest quintile of TG (TG range 190 to $838 \mathrm{mg} / \mathrm{dl}$ ) and HDL categories as specified on $\mathrm{x}$-axis. Downward pointing triangles, OR estimates for those in third quintile of TG (TG range 102 to $133 \mathrm{mg}$ / dl); upward pointing triangles, estimates for those in lowest quintile of TG (TG range 22 to $72 \mathrm{mg} / \mathrm{dl}$ ). Reference category was the set of subjects with lowest TG and highest HDL categories (TG range 22 to $72 \mathrm{mg} / \mathrm{dl}$, HDL range 7 to $30 \mathrm{mg} / \mathrm{dl}$, OR 1.0). Estimates and 95\% confidence interval derived from model 6 of Table 2. 
Table 1

Demographic, biomarker, and coronary heart disease (CHD) events for cases and controls

\begin{tabular}{|c|c|c|c|}
\hline Characteristic & $\begin{array}{r}\text { Overall } \\
(\mathbf{n}=\mathbf{3 4 5})\end{array}$ & $\begin{array}{c}\text { Patients } \\
(\mathbf{n}=170)\end{array}$ & $\begin{array}{l}\text { Controls } \\
(\mathrm{n}=175)\end{array}$ \\
\hline Men & $211(61 \%)$ & $127(75 \%)$ & $84(48 \%)$ \\
\hline White & $279(81 \%)$ & $150(88 \%)$ & $131(75 \%)$ \\
\hline Mean age \pm SD (years) & $66 \pm 9$ & $66 \pm 9$ & \pm 10 \\
\hline \multicolumn{4}{|l|}{ Mean serum lipid level \pm SD (mg/dl) } \\
\hline Total cholesterol & $150 \pm 36$ & $139 \pm 30$ & $160 \pm 38$ \\
\hline Low-density lipoprotein cholesterol & $80 \pm 26$ & $73 \pm 24$ & $87 \pm 36$ \\
\hline High-density lipoprotein cholesterol & $42 \pm 15$ & $37 \pm 12$ & $47 \pm 16$ \\
\hline Triglycerides & $142 \pm 93$ & $147 \pm 82$ & $136 \pm 103$ \\
\hline Lipid-lowering drugs at admission & $161(47 \%)$ & $104(61 \%)$ & $57(33 \%)$ \\
\hline Stage 1 hypertension $(\mathrm{n}=249)$ & $82(33 \%)$ & $36(31 \%)$ & $46(35 \%)$ \\
\hline \multicolumn{4}{|l|}{ Coronary heart disease event } \\
\hline Non-ST-segment elevation myocardial infarction & - & $42(25 \%)$ & - \\
\hline ST-segment elevation myocardial infarction & - & $34(20 \%)$ & - \\
\hline Unstable angina pectoris & - & $74(44 \%)$ & - \\
\hline Recent-onset angina pectoris & - & $18(11 \%)$ & - \\
\hline Acute coronary syndrome & - & $2(1 \%)$ & - \\
\hline Previous myocardial infarction & - & $27(16 \%)$ & - \\
\hline Previous coronary event & - & $24(14 \%)$ & - \\
\hline Previous angioplasty & - & $33(19)$ & - \\
\hline Chronic stable angina & - & $3(2 \%)$ & - \\
\hline Other previous evidence of coronary heart disease & - & $2(1 \%)$ & - \\
\hline \multicolumn{4}{|l|}{ Discharge diagnosis for controls } \\
\hline Chest pain, noncardiac & - & - & $28(16 \%)$ \\
\hline Gastroenterologic & - & - & $30(17 \%)$ \\
\hline Orthopedic & - & - & $14(8 \%)$ \\
\hline Neurologic, other than ischemic stroke & - & - & $40(23 \%)$ \\
\hline Cardiac arrhythmia & - & - & $12(7 \%)$ \\
\hline Cardiac valvular & - & - & $15(9 \%)$ \\
\hline Pulmonary & - & - & $10(6 \%)$ \\
\hline Other ${ }^{*}$ & - & - & $26(15 \%)$ \\
\hline
\end{tabular}

Other diagnoses included alcoholism $(n=1)$, anemia $(n=1)$, abdominal aortic aneurysm $(n=1)$, infection $(n=2)$, circumcision $(n=1)$, dehydration $(n=1)$, eosinophilia $(n=1)$, gynecologic $(n=2)$, hypertension $(n=4)$, hypoglycemia $(n=1)$, urinary $(n=4)$, pulmonary embolus $(n=$ $2)$, pericarditis $(n=1)$, thromobosis $(n=1)$, and thyroid $(n=3)$. 


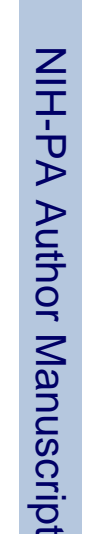

ㄴ.
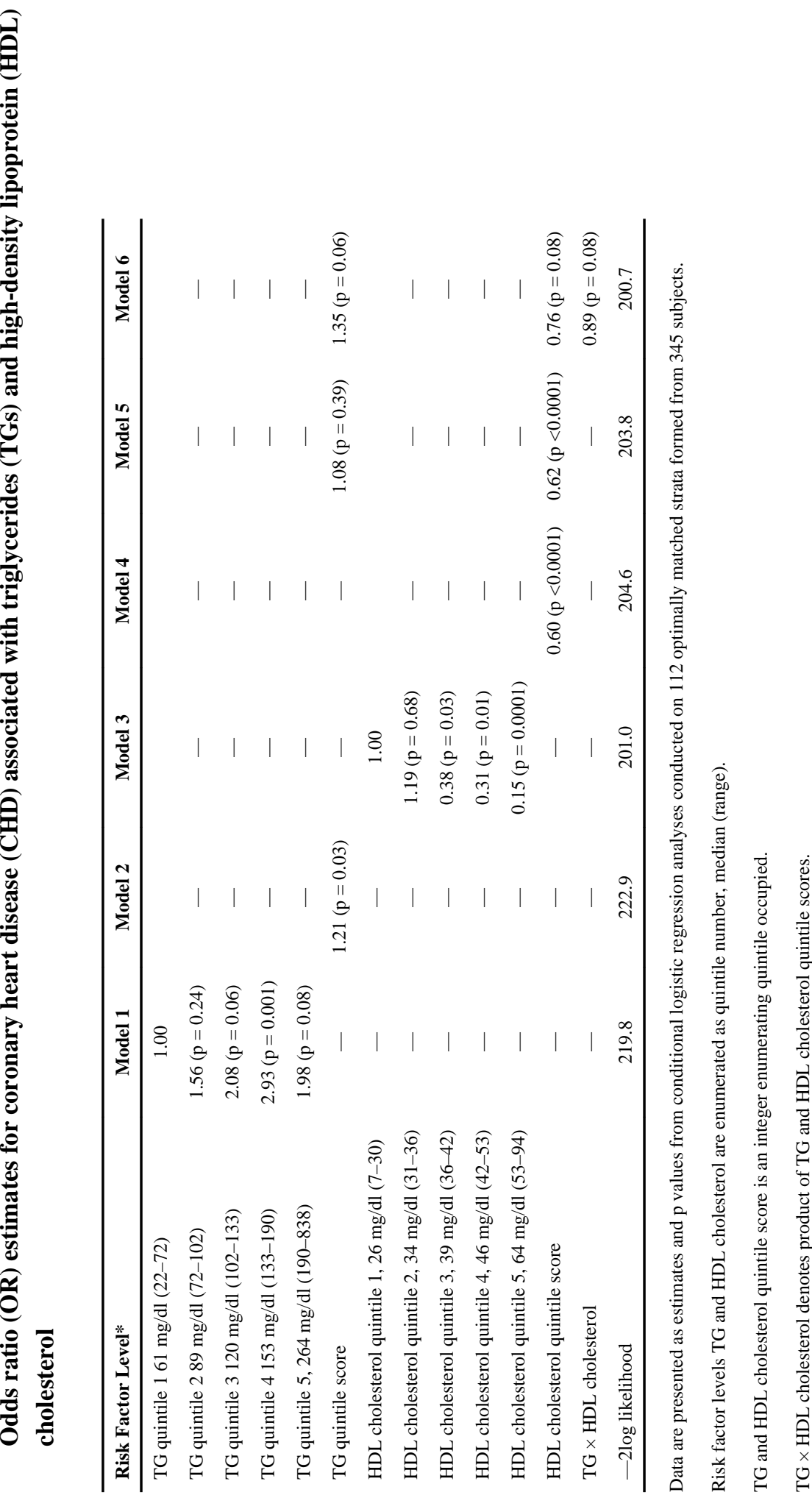


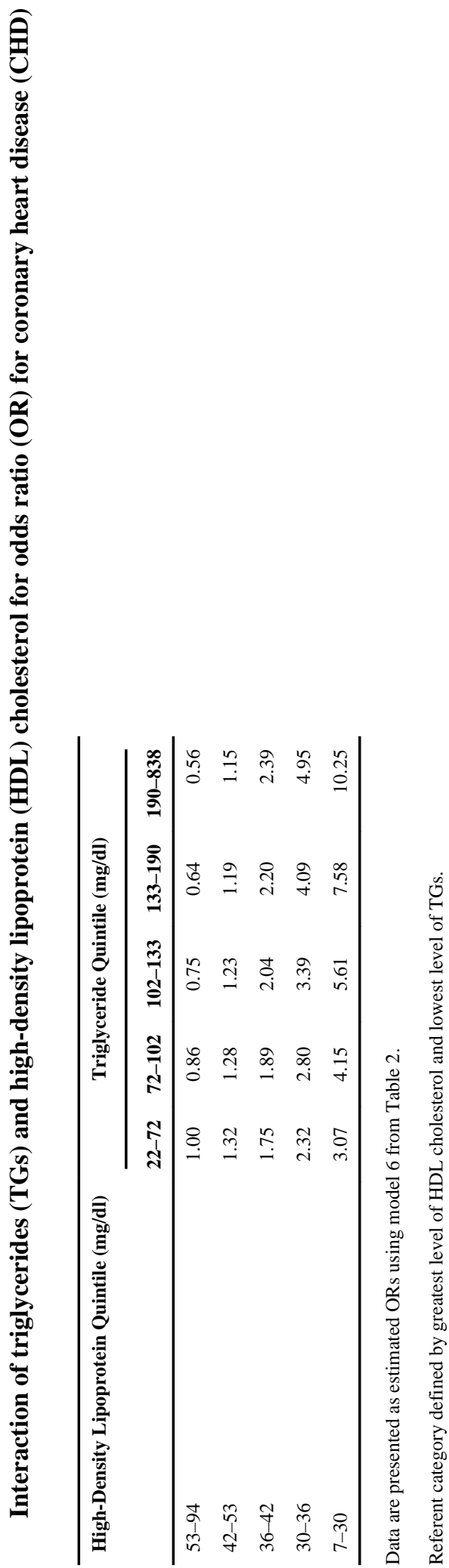


Table 4

Odds ratio (OR) estimates for triglycerides (TGs) and high-density lipoprotein (HDL) cholesterol for those with low-density lipoprotein (LDL) cholesterol $<70 \mathrm{mg} / \mathrm{dl}$

\begin{tabular}{lcccc}
\hline Variable & Model 7 & Model 8 & Model 9 & Model 10 \\
\hline TG tertile score & $2.263(\mathrm{p}=0.002)$ & - & $2.172(\mathrm{p}=0.0045)$ & $3.492(\mathrm{p}=0.011)$ \\
HDL cholesterol tertile score & - & $0.586(\mathrm{p}=0.0714)$ & $0.644(\mathrm{p}=0.182)$ & $1.034(\mathrm{p}=0.950)$ \\
TG $\times$ HDL & - & - & - & $0.638(\mathrm{p}=0.206)$ \\
$-2 \log$ likelihood & 76.4 & 83.8 & 74.5 & 72.8 \\
\hline
\end{tabular}

Data are presented as estimated ORs obtained using conditional logistic regression analysis of 41 optimally matched strata formed from 128 subjects with LDL cholesterol $<70 \mathrm{mg} / \mathrm{dl}$.

Tertile intervals for TGs were 36-91 mg/dl, 91-152 mg/dl, and 152-479 mg/dl, with a median of 68, 121, and 219, respectively.

Tertile intervals for HDL cholesterol were 7-30 mg/dl, 30-37 mg/dl, and 37-86, with a median of 25, 34, and 46, respectively. 